\title{
Chemistry of the Main Component of Essential Oil of Litsea cubeba and Its Derivatives
}

\author{
Lisong Hu, Menghao Du, Jingping Zhang, Yangdong Wang \\ Research Institute of Subtropical Forestry Chinese Academy of Forestry, Fuyang, China \\ Email: lisohu@hotmail.com
}

Received 8 July 2014; revised 11 August 2014; accepted 26 August 2014

Copyright (C) 2014 by authors and Scientific Research Publishing Inc.

This work is licensed under the Creative Commons Attribution International License (CC BY). http://creativecommons.org/licenses/by/4.0/

\section{Abstract}

The tree of Litsea cubeba is widely spread in China, Indonesia and other part of Southeast Asia. The essential oil of Litsea cubeba (EOLC) is obtained by steam distillation from the pepper-like fruits tree Litsea cubeba. The EOLC consists of about 29 active compounds. Among them, citral is the main component; the content of citral is nearly $80 \%$ of the EOLC. Due to the special function group, citral is easy to react with many chemicals. Thus, EOLC is usually applied as starting material to carry out aldol condensation, reduction, and six-member ring forming reaction. The EOLC is extensively employed to synthesis of geranal nitriles, pseudonoe, ionone, methyl ionone, Vitamin E and Vitamin A. These products are broadly applied in the fields of fragrance, perfume, medicine and so on. This paper presents comprehensive utilization of EOLC as raw materials to synthesize many active chemicals.

\section{Keywords}

Litsea cubeba, Essential Oil, Citral, Synthesis

\section{Introduction}

In the recent years, the utilization of essential oil both in daily life and industry has increased exponentially as use of one or more components from plants like pinus (Packer et al., 1999; Ayrilmis et al., 2009), Litsea cubeba, Cinnamomum camphora (Linn.) Presl (Stubbs et al., 2004; Qian et al., 2012) and so on. Essential oil is extensively used in medicine, nutrition, flavoring, beverages, dyeing, repellents, fragrances, cosmetics (Djeridane et al., 2006). For many years, utilization of essential oil has played increasingly important role in the strategy of chemistry industry field (Isman, 2000). As a part of this preoccupation, the researches for high efficient, green, 
and high valued components from active plants are of vital concern. In addition, compared to the active components obtained by solvent extraction and synthesis, essential oils are commonly obtained by water vapor distillation, thus essential oils are eco-friendly, low-toxicity. Furthermore, most of essential oils have excellent effects on benefiting human beings in food, medicine, perfume and fragrance (Bakkali et al., 2008).

The essential oil of Litsea cubeba is obtained by steam distillation from the pepper-like fruits (Figure 1) Litsea cubeba (Figure 2). The tree is widely spread in China, Indonesia and other part of Southeast Asia, where it occurs in mountainous region. In ancient China, the EOLC is employed as medicine for headache, fatigue, muscle pain and depression (Chen et al., 2013). Nowadays, The EOLC is extensively employed to prepare geranal nitriles, pseudonoe, ionone, methyl ionone, Vitamin E and Vitamin A. Herein, we report the chemistry of the EOLC and main components of EOLC as starting materials in chemistry and industry.

\section{Ease of Use}

\subsection{Chemistry of the EOLC}

The EOLC had been analyzed by several researchers (Ye, 1992; Cheng, 1995; Liu et al., 2001; Wang et al., 2002). Recently, it reported that the essential oil of Litsea cubeba contained 29 compounds (see Table 1) (Hu et al., 2011), which mainly contains terpenes, lipids and fatty acids. On account of one of the double bonds binding with four different groups, citral has two geometric isomers, which are the $\mathrm{E}$ isomer (geranial) and the $\mathrm{Z}$ isomer (neral) (Scheme 1). The content of citral in EOLC was as high as $70 \%$. The content of limonene was $10 \%$ and the content of other components was $20 \%$ approximately (Table 1). The experiments details as follows:

\subsubsection{Materials and Chemicals}

Litsea cubeba Fruits were obtained from local Litsea cubeba trees within $6 \mathrm{~h}$ stored at $-20^{\circ} \mathrm{C}$ in freezer.

Chemicals and Reagents. Standards were purchased from Sigma-Aldrich Company (American). The solvents were analytical grade and without treatment before use.

\subsubsection{Extracting EOLC}

EOLC were obtained through vapor distillation of the fruits of Litsea cubeba. General procedure was as follows: $5 \mathrm{~g}$ fruits of Litsea cubeba were added into $250 \mathrm{ml}$ round bottom flask with $100 \mathrm{ml}$ water and using vapor distillation equipment for vapor supplying, collecting the oil and dried with sodium sulfate and concentrated by vacuum rotary evaporator to $2 \mathrm{ml}$. Followed by further concentration to $0.2 \mathrm{ml}$ using a flow of nitrogen.

\subsubsection{GC, GC-MS Analysis}

GC analysis was performed on an Agilent 6890. The gas chromatography was equipped with a FID. The separation was performed using a nonpolar fused silica capillary column HP-5 (5\% Phenyl Methyl Siloxane, Agilent $19091 \mathrm{~J}-413), 30.0 \mathrm{~m} \times 0.32 \mathrm{~mm}$ coated with $0.25 \mu \mathrm{m}$ film thickness. Carrier gas (Nitrogen) at flow rate of $1 \mathrm{ml} / \mathrm{min}$. Column temperature program was $50^{\circ} \mathrm{C}$ for 5 min and then programmed to $85^{\circ} \mathrm{C}$ for $2 \mathrm{~min}$ at $5^{\circ} \mathrm{C} / \mathrm{min}$, then increased to $280^{\circ} \mathrm{C}$ for $10 \mathrm{~min}$ at $3^{\circ} \mathrm{C} / \mathrm{min}$.

GC-MS analysis were performed on a HP6890 gas chromatograph equipped with a HP 5973 mass selective detector using a $30 \mathrm{~m} \times 0.25 \mathrm{~mm}$ id., $0.25 \mu \mathrm{m}$ film thickness HP-5 capillary column (5\% Phenyl Methyl Siloxane, Agilent $19091 \mathrm{~J}-413$ ) with helium as carrier gas. Column temperature program was $50^{\circ} \mathrm{C}$ for 5 min and then programmed to $85^{\circ} \mathrm{C}$ for $2 \mathrm{~min}$ at $5^{\circ} \mathrm{C} / \mathrm{min}$, then increased to $280^{\circ} \mathrm{C}$ for $10 \mathrm{~min}$ at $3^{\circ} \mathrm{C} / \mathrm{min}$.

Volatile compounds were identified by comparing their mass spectra with the mass spectra from MS database (NIST 05, WILEY 7). When available, MS identifications were confirmed by comparing GC retention times of the analysts with those from pure standards. The identification was confirmed by using retention indices (RI) of the value compared with those reported in the literature (Jordan, M. J. et al., 2002). Linear retention indices of the compounds were calculated using a series of n-alkanes $\left(\mathrm{C}_{7}-\mathrm{C}_{30}\right.$, Sigma-Aldrich, America) injected in the same conditions. When standard chemicals were not available, tentative identification was carried out by matching the mass spectra. The results were given in Table 1.

\subsection{Synthesis of Geranyl Nitrile}

Geranyl nitrile with lemony-fresh odor similar to citral (Calkin and Jellinek, 1994) is widely used as fragrance 


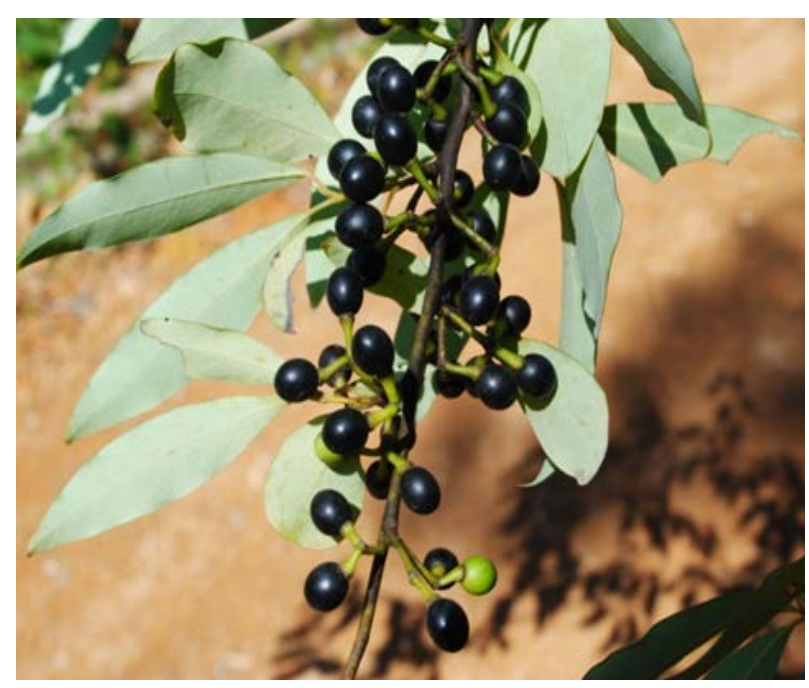

Figure 1. Fruits of Litsea cubeba.

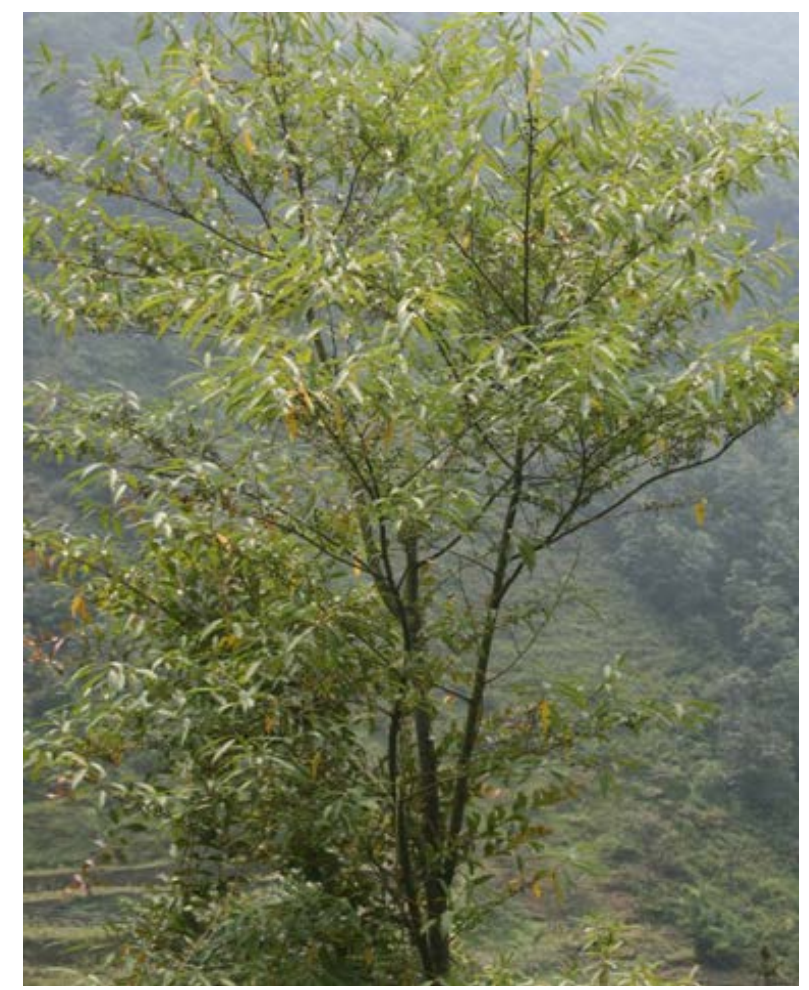

Figure 2. The tree of the Listea cubeba.<smiles>CC(C)=CCC=C(C)CC=O</smiles><smiles>CC(C)=CCC=C(C)C=O</smiles>

Scheme 1. The two geometric isomers of citral.

ingredients and incorporated into a variety of consumer product types, including soaps, shampoos, cosmetics, perfumes, detergents and insect repellents (Potter et al., 2001; Arctander, 1969). The geranyl nitrile is appre- 
Table 1. Chemical composition (\%) of EOLC (Hu, 2011).

\begin{tabular}{|c|c|c|c|}
\hline Components & $\mathbf{R} \mathbf{I}^{\mathbf{a}}$ & Peak area (\%) & Identification method \\
\hline$\alpha$-Pinene & 932 & 0.58 & GC-MS \\
\hline$\beta$-Phellandrene & 946 & trace & GC-MS \\
\hline Camphene & 956 & 0.48 & GC-MS \\
\hline$\beta$-Pinene & 978 & 0.19 & GC-MS \\
\hline 6-Methyl-5-en-2-one & 988 & trace & GC-MS, RI \\
\hline p-Cymene & 993 & 1.22 & GC-MS \\
\hline Cineole & 1032 & trace & GC-MS, RI \\
\hline$d$-Limonene & 1041 & 8.52 & GC-MS, RI ${ }^{\mathrm{d}}$ \\
\hline$\gamma$-Terpinene & 1045 & 0.58 & GC-MS, RI \\
\hline Linalool & 1104 & 1.36 & GC-MS, RI \\
\hline cis-Limonene oxide & 1132 & 0.85 & GC-MS, RI \\
\hline Thujanol & 1139 & 0.98 & GC-MS, RI \\
\hline (E)-p-Menth-2-en-ol & 1140 & 0.74 & GC-MS, RI \\
\hline Citronellal & 1152 & 0.94 & GC-MS, RI \\
\hline Borneol & 1165 & 0.2 & GC-MS,RT \\
\hline Terpinene-4-ol & 1178 & 0.27 & GC-MS \\
\hline$\alpha$-Terpineneol & 1196 & 0.63 & GC-MS \\
\hline citronellol & 1217 & 0.48 & GC-MS \\
\hline$\beta$-Citral & 1248 & 26.15 & GC-MS, RT \\
\hline Nerol & 1257 & 0.98 & GC-MS \\
\hline$\alpha$-Citral & 1265 & 33.16 & GC-MS, RT \\
\hline Bornyl acetate & 1282 & 3.98 & GC-MS, RI \\
\hline Eugenol & 1358 & 1.19 & GC-MS, RI \\
\hline Caryophyllene & 1454 & 3.47 & GC-MS, RI \\
\hline Ethyl myristate & 1791 & 1.87 & GC-MS \\
\hline Palmitic acid & 1971 & 1.16 & GC-MS \\
\hline Ethyl palmitate & 1993 & 2.25 & GC-MS \\
\hline Methyl oleate & 2094 & 0.57 & GC-MS \\
\hline Linoleic acid ethyl ester & 2144 & 1.32 & GC-MS \\
\hline Ethyl oleate & 2176 & 1.72 & GC-MS \\
\hline
\end{tabular}

${ }^{\mathrm{a}}$ Retention Index; ${ }^{\mathrm{b}}$ Indentified by good match of mass spectrometer; ${ }^{\mathrm{c}}$ Identified by retention index and compared with those reported in the literature (Qin, 2008); dIdentified by retention time of standard compounds.

ciated for its comparative stability under mildly alkaline conditions, which makes it particularly suitable to applications in soaps, detergents.

Zheng reported citral directly reacting with ammonia in the presence of active copper and molecular sieve as catalyst. The yield could reach 90\% (Scheme 2). However the reaction demonstrated some disadvantages: Firstly, the reaction endured so high temperature that the reaction led to more energy consuming; Secondly, this reaction had many side reactions, thus the product was difficult for purification. In 2001, Nong adopted tetrabutylammonium bromide as transfer phase catalyst, and acetic anhydride as dehydrant in mild condition to synthesis of geranyl nitrile; and the yield was 91\% (Nong et al., 2001). Zhou carried out the reaction with hydroxyl amine sulftrate. This procedure was more facile and convenient. And yields were good to excellent. However, excess amount of citral was employed (Zhou et al., 2005).

\subsection{Synthesis of Pseudoionone}

Pseudoionone is a key intermediate for preparation of ionone. Usually, pseudoionoine is applied in fragrance, food additives and perfume field (Rajuet et al., 2011).

Pseudoionone is prepared by citral condensing with acetone in the presence of catalysts (Scheme 3) basically. 


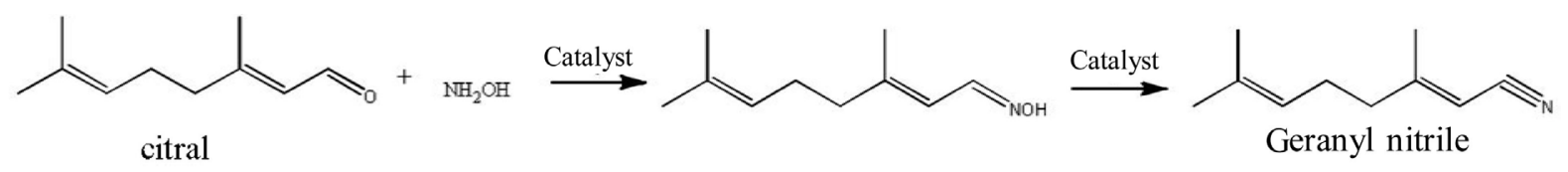

Scheme 2. Synthesis of geranyl nitrile with ammonia.

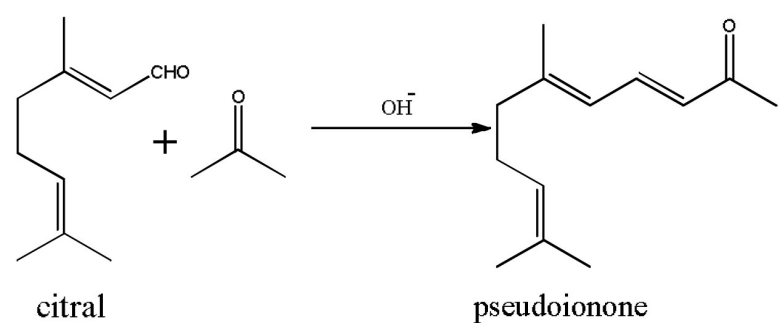

Scheme 3. Preparation of pseudoionone using citral and acetone as starting materials.

This reaction is simple and facile to carry out. Researchers were focusing on exploring the catalysts. Zhou reported the aldol condensation between citral and acetone. The reaction was performed by using catalytic amount of sodium hydroxide or potassium hydroxide (2\%) in the presence of 6 equivalents of acetone; moderate to good yields were obtained (Zhou et al., 2009). Catalyst was crucial for the reactions, and many catalysts were screened and modified for improving the reactions, such as: EtONa/EtOH (Wang, 1990), KOH/MeOH (Wang and Jiang, 1993) and so on. The yields of the reactions could get $86 \%$, and purity could get $97 \%$. However, there were still many side reactions such as citral self-condensation, acetone self-condensation and so on occurring in the reaction.

\subsection{Synthesis of Methyl Ionone}

Methyl ionone known as high-grade fragrance with fresh odor is mainly used in fragrance and food additives. In 1980, Guo described the synthesis of methyl ionone use $\mathrm{KOH}$ and methanol as condensation agent, and the yield was $89 \%$. Meanwhile, using phosphoric acid as cyclization agent, and the yield was 70\% (Guo et al., 1980). In 2002, Lin investigated macroreticular resin as catalysts for cyclization of the pseudomethylionone to produce methylionone (Lin and Liang, 2002; Tang, 2011). The methyl ionone could be prepared by aldol condensation and ring-closed reaction (Scheme 4). The typical procedures were as follows: methyl acetone in $250 \mathrm{ml}$ flask added $5 \% \mathrm{NaOH} 30 \mathrm{ml}$ with stirring, then dropped EOLC at $35^{\circ} \mathrm{C}-40^{\circ} \mathrm{C}$ for a few hours in the presence of catalysts. In 2003, Huang reported that citral and 2-butyl acetone as starting materials in the presence of quaternary ammonium hydroxide and solid super acid $\mathrm{TiO}_{2} / \mathrm{SO}_{4}{ }^{2-}$ as catalyst. Yields were $90 \%-92 \%$. However, the dimethyl benzene as solvent was difficult to remove off from the products. In 2004, Lin developed a new method: the anion exchange resin as catalyst, the yield was quantitative, but the large amount of catalyst was consumed (Lin 2004).

\subsection{Synthesis of $\beta$-Ionone}

$\beta$-ionone, an important contributor to fragrance in many flowers (Kaiser and Lamparsky, 1980; Cooperet et al., 2003), is an abundant source of useful aroma compounds existing in a variety of essential oils with various application in fragrance, perfume industry. In addition, $\beta$-ionone is key intermediate to prepare vitamin $\mathrm{E}$, vitamin A and extensively used in cosmetics (Kanei et al., 1999), food flavor and inhibitor (Yu et al., 1995; Plotto et al., 2006).

Citral condensing with acetone under base condition is the typical method of synthesis of $\beta$-ionone, then through ring-closure reaction forming $\beta$-ionone in the presence of catalyst (Scheme 5) (Hertel et al., 1986). During the whole reaction, selecting the excellent catalyst is vital for the whole reactions. Hence, many researchers had been working on the selecting and applying catalysts such as sodium hydride, $\mathrm{KF} / \mathrm{Al}_{2} \mathrm{O}_{3}, \mathrm{LiOH}$ (Lu and Yao, 2007; Zhang et al., 2010), phosphoric acid. Transfer phase catalyst Bu4N $\mathrm{N}^{+} \mathrm{Br}^{-}, \mathrm{Et}_{3} \mathrm{~N}^{+} \mathrm{CH}_{2} \mathrm{PHCl}^{-}$(Liu et al., 2000). The yields varied from mediate to good. 


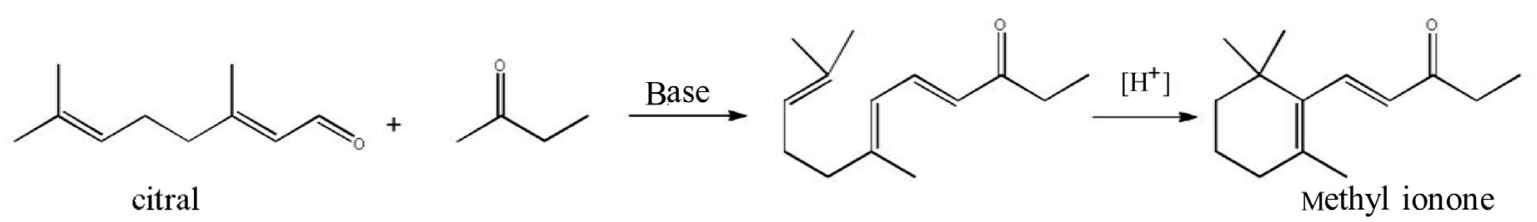

Scheme 4. Synthesis of Methyl ionone.

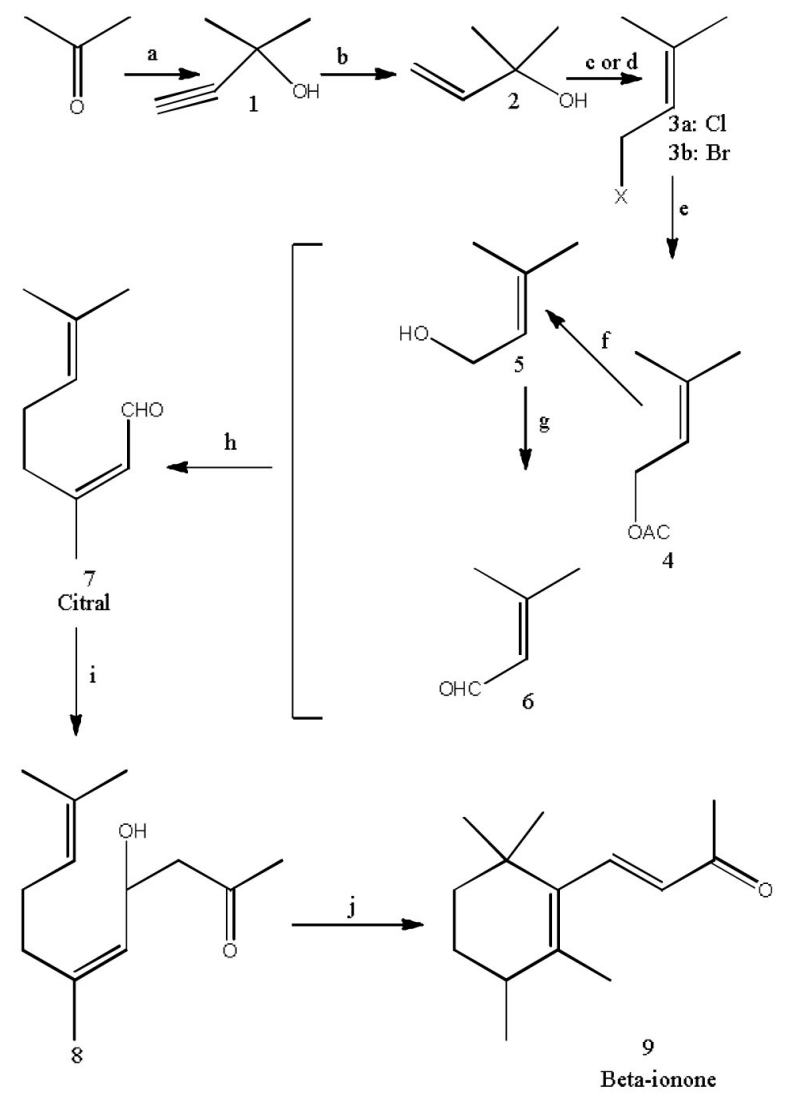

Scheme 5. Typical method of synthesis of $\beta$-ionone.

\subsection{Synthesis of Vitamin A}

Vitamin A is a group of unsaturated nutritional organic compounds, which includes retinol, retinal, retinoic acid, and several provitamin A carotenoids (Damodaran and Parkin, 2008). Vitamin A is a vital medicine, which is widely used for nyctalopia, eye and skin dryness. It is important for growth and development for the maintenance of the immune system and vision (Tanumihardjo, 2011).

Vitamin A was first synthesized in 1947 by two Dutch chemists. Then, scientists and industry managed to commercialize Vitamin A (Robeson et al., 1955). Vitamin A has a special structure: $\beta$-ionone ring to which an isoprenoid chain attached. In 1947, the Roche Company commercialized the product using beta-ionone as starting materials through Dazens reaction, Grignard reaction, hydrogenation acetylation, bromination, elimination (Scheme 6). However, 50 more reagents were employed and many reaction units were employed. Years later, BASF Company invented a new route that beta-ionone as starting materials underwent ethynylation, reduction and elimination. This synthetic pathway was simple and economical. Meanwhile the yield was high. However, the drawbacks were secondary key intermediates $\mathrm{C}_{5}$ aldehyde difficult to synthesizing.

\subsection{Synthesis of Vitamin E}

Vitamin $\mathrm{E}$ is the most important industrial fat-soluble antioxidant, which includes tocopherols and tocotrienols, 


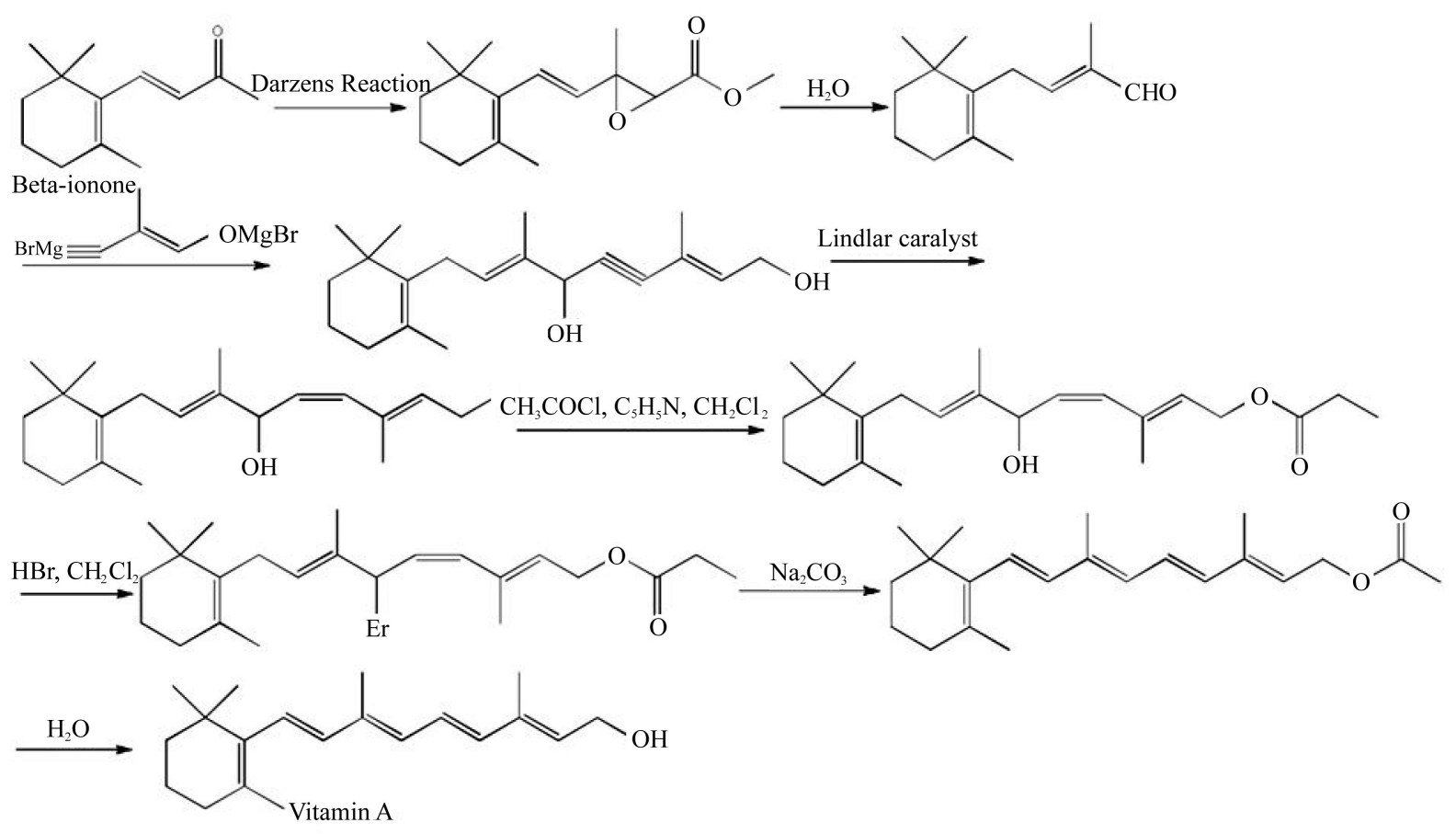

Scheme 6. Synthesis of Vitamin A.

extensively applied as antioxidant, anti-cancer drugs, free radical scavenger (Bowry et al., 1995). Vitamin E could improve human physical immunity, and used as animal feeds (Bonrath et al., 2007).

Vitamin E, generally, is synthesized by two building blocks through the Friedel-Crafts alkylation reaction. One building block is 2,3,5-trimethyl hydroquinone (TMHQ), and the other building block is isophytol (Scheme 7). And the mechanism of the reaction is enol under the catalyst of $\mathrm{AlCl}_{3}$ forming carbocations binding with TMHQ. To date, there are only four companies producing Vitamin E in large scale. Isophytol is a key material for the synthesis of vitamin E. Usually, isophytol was synthesized by using citral or pseudoionone as starting materials, through serials of reactions (Sato et al., 1963). And the study to date was focused on catalyst selecting and modification. Many solid acids were applied to replace the liquid acid. Qian used phosphomolybdic acid as catalyst obtained good yield. The purity could get 88\% (Qian et al., 1999). Makoto employed scandium (III) trifluoromethanesulfonate as an efficient catalyst (Matsui et al., 1995). Bulychev employed amine as catalyst (Bulychev and Kartsev, 1999).

\subsection{Synthesis of Nitrogen Derivatives}

The citral could condensation with amines and amino acids. Saddiq used citral reacted with cytosine, this product showed the good antibacterial and antifungal activity, especially on staphylococcus aureus (Saddiq and Khayyat, 2010). And the synthesis route as follow (Scheme 8).

Chitosan, a biocompatible, biodegradable, non-toxic polymer, is prepared from chitin, which is the second most naturally occurring biopolymer after cellulose. The Schiff base of chitosan was synthesized by the reaction of chitosan with citral under high-intensity ultrasound (Scheme 9). The effect of the molar ratio of chitosan to citral, reaction time, and temperature on the yield has been investigated. The optimal conditions were a temperature of $50^{\circ} \mathrm{C}$, a molar ratio of chitosan to citral of 1:6, and a reaction time of $10 \mathrm{~h}$. The maximum yield achieved was $86.4 \%$ under optimum conditions. The structure of the schiff base was characterized by FTIR spectroscopy, elemental analysis, and X-ray diffraction studies. The strong peaks at 1648.3 and $1610.6 \mathrm{~cm}^{-1}$ are due to C-N bond and C-C bond stretching vibrations. The results confirmed that amino groups on chitosan reacted with citral to form the Schiff base. The antimicrobial activities of chitosan and Schiff base of chitosan were investigated against Escherichia coli, Staphylococcus aureus, and Aspergillus niger. The results indicate that the antimicrobial activity of the Schiff base increases with an increase in the concentration. It was also found that the 


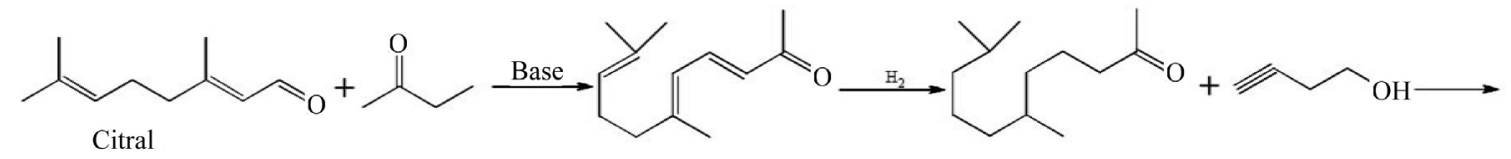<smiles>CC(C)CCCC(C)CCCC(C)(O)C#CCO</smiles>

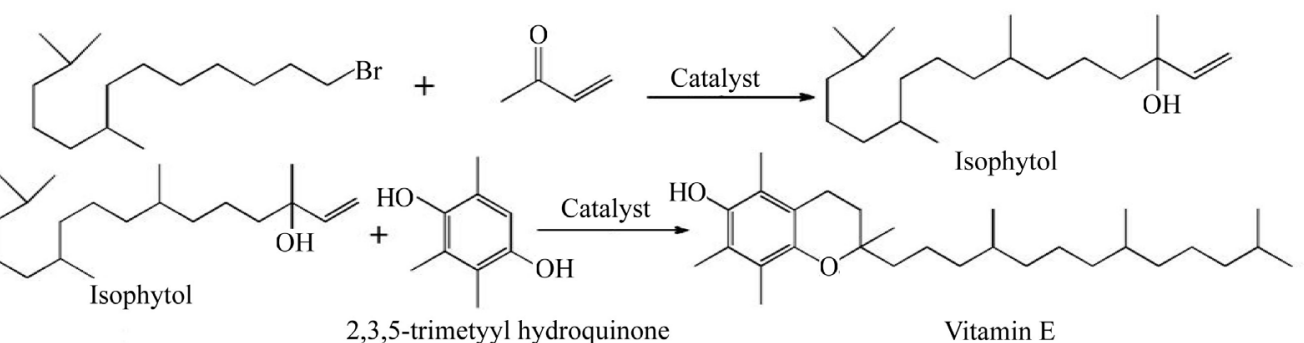

Scheme 7. Synthesis of Vitamin E.

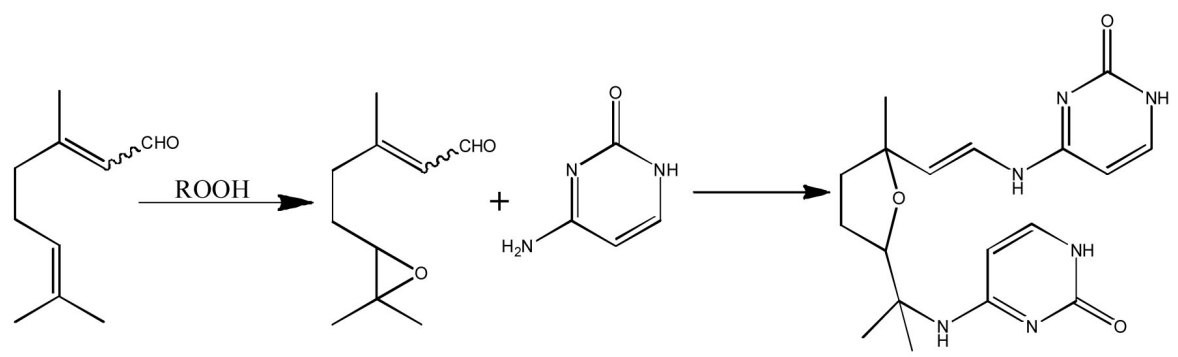

Scheme 8. Synthesis of nitrogen derivatives with nitral as starting materials.
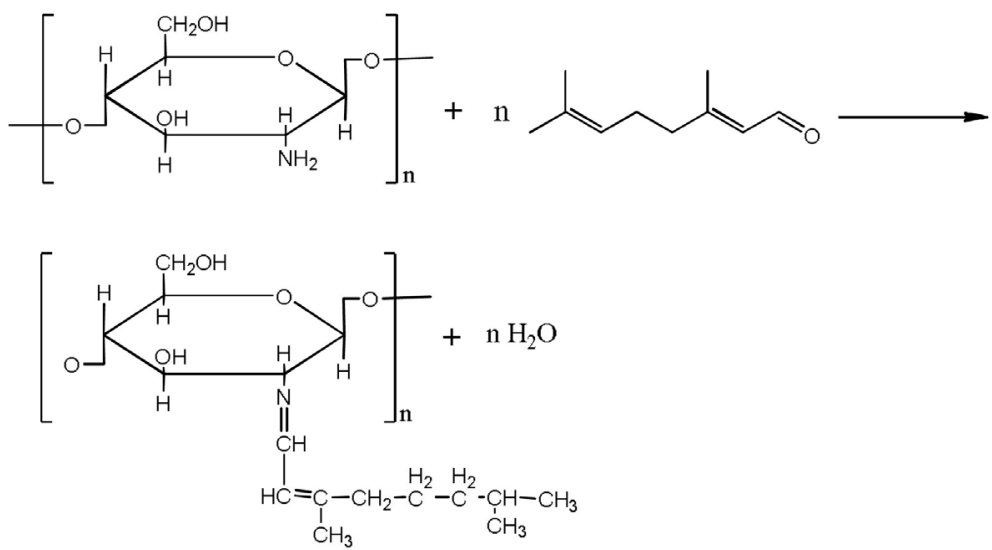

Scheme 9. Synthesis of chitosan derivatives.

antimicrobial activity of the Schiff base was stronger than that of chitosan (Jin, 2009).

\section{Conclusion}

With the information to date, it has shown that the EOLC could be employed to synthesis such as pseudoione, iodone, methyl iodone, Vitamin E, Vitamin A and so on. These products were widely applied in perfume, fragrance, food flavor, anti-inflammatory, anti-bacterial, and antifungal medicine. Some products are very popular 
in daily life. Some new nitrogen derivatives from EOLC could also discover some new functions.

As shown in this review, despite of much research works and application, improvements had been done on the chemical utilization of EOLC. However, most of the research work was focused on modifying and selecting the catalysts for improving yields or simplifying the reaction procedures; exploiting new EOLC based compounds to expand the utilization of the EOLC needs much more work. On the other hand, besides the citral, the EOLC has many other components such as lipids and fatty acids; these compounds should be well studied.

\section{Acknowledgements}

This work was financial supported by the Zhejiang Provincial Natural Science Foundation of China (Grant No. Y3110321).

\section{References}

Ayrilmis, N., Buyuksari, U., Avci, E., \& Koc, E. (2009). Utilization of Pine (Pinus pinea L.) Cone in Manufacture of Wood Based Composite. Forest Ecology and Management, 259, 65-70. http://dx.doi.org/10.1016/j.foreco.2009.09.043

Bakkali, F., Averbeck, S., Averbeck, D., \& Idaomar, M. (2008). Biological Effects of Essential Oils—A Review. Food and Chemical Toxicology, 46, 446-475.

Bonrath, W., Dittel, C., Giraudi, L., Netscher, T., \& Pabst, T. (2007). Rare Earth Triflate Catalysts in the Synthesis of Vitamin E and Its Derivatives. Catalysis Today, 121, 65-70. http://dx.doi.org/10.1016/j.cattod.2006.11.022

Bowry, V. W., Mohr, D., Cleary, J., \& Stocker, R. (1995). Prevention of Tocopherol-Mediated Peroxidation in Ubiquinol-10-Free Human Low Density Lipoprotein. Journal of Biological Chemistry, 270, 5756-5763. http://dx.doi.org/10.1074/jbc.270.11.5756

Bulychev, É. Y., \& Kartsev, G. (1999). On the Mechanism of $\alpha$-Tocopherol Synthesis. Effect of Amines on the Yield and Purity of $\alpha$-Tocopherol. Pharmaceutical Chemistry Journal, 33, 267-268.

Chen, Y., Wang, Y., Han, X., Si, L., Wu, Q., \& Lin, L. (2013). Biology and Chemistry of Litsea cubeba, a Promising Industrial Tree in China. Journal of Essential Oil Research, 25, 103-111. http://dx.doi.org/10.1080/10412905.2012.751559

Cheng, K. (1995). Raising Citral Content of Litsea cubeba Oil by Reduced-Pressure Distillation. Hunan Chemistry Industry, 25, 34-36.

Cooper, C. M., Davies, N. W., \& Menary, R. C. (2003). C-27 Apocarotenoids in the Flowers of Boronia megastigma (Nees). Journal of Agricultural and Food Chemistry, 51, 2384-2389. http://dx.doi.org/10.1021/jf026007c

Damodaran, S., \& Parkin, K. L. (2008). Fennema's Food Chemistry. Boca Raton, FL: CRC Press.

Djeridane, A., Yousfi, M., Nadjemi, B., Boutassouna, D., Stocker, P., \& Vidal, N. (2006). Antioxidant Activity of Some Algerian Medicinal Plants Extracts Containing Phenolic Compounds. Food Chemistry, 97, 654-660. http://dx.doi.org/10.1016/j.foodchem.2005.04.028

Guo, M., Wang, D., Jiang, M., \& Xiao, Y. (1980). The Study of Modification of Iso-Methyl Ionone, Methyl Ionone Process. Flavor and Perfume, 5, 1-11.

Hu, L., Yang, W., Du, M., \& Zhang, J. (2011). Characterization of the Volatiles and Active Components in Ethanol Extracts of Fruits of Litsea cubeba (Lour.) by Gas Chromatography-Mass Spectrometry (GC-MS) and Gas Chromatography-Olfactometry (GC-O). Journal of Medicinal Plants Research, 5, 3298-3303.

Isman, M. B. (2000). Plant Essential Oils for Pest and Disease Management. Crop Protection, 19, 603-608. http://dx.doi.org/10.1016/S0261-2194(00)00079-X

Jin, X., Wang, J., \& Bai, J. (2009). Synthesis and Antimicrobial Activity of the Schiff Base from Chitosan and Citral. Carbohydrate Research, 344, 825-829. http://dx.doi.org/10.1016/j.carres.2009.01.022

Jordan, M. J., Margaria, C. A., Shaw, P. E., \& Goodner, K. L. (2002). Aroma Active Components in Aqueous Kiwi Fruit Essence and Kiwi Fruit Puree by GC-MS and Multidimensional GC/GC-O. Journal of Agricultural and Food Chemistry, 50, 5386-5390.

Kaiser, R., \& Lamparsky, D. (1980). Volatile Constituents of Osmanthus Absolute. In B. D. Mookheijee, \& C. J. Mussinan (Eds.), Essential Oils (pp. 159-192). Wheaton, IL: Allured Publishing.

Kanei, N., Tamura, Y., \& Kunieda, H. (1999). Effect of Types of Perfume Compounds on the Hydrophile-Lipophile Balance Temperature. Journal of Colloid and Interface Science, 218, 13-22. http://dx.doi.org/10.1006/jcis.1999.6371

Lin, H. (2004). Synthesis of Pseudomethylionone Using Fluoride Ion Supported on Anion Exchange Resin as a Catalyst. Chinese Journal of Synthetic Chemistry, 12, 402-404.

Lin, H., \& Liang, C. (2002). Cyclization of Pseudomethylionone by Catalyzing of Macroreticular Resin. Liaoning Chemical 
Industry July, 31, 3.

Liu, R., Liu, H., \& Dong, A. (2000). Study on the Synthesis of Ionone Violet in the Presence of Phase Transfer Catalysis. Speciality Petrochemicals, 200, 31-33.

Liu, X., Chen, M., \& Chen, X. (2001). Extracting Citral from Litsea cubeba Fruits and Determination of Citral. Chemistry and Industry of Forest Products, 21, 87-90.

Lu, J., \& Yao, Y. (2007). Improvement on the Synthesis of Beta-Ionone. Guizhou Chemical Industry, 32, 12-14.

Matsui, M., Karibe, N., Hayashi, K., \& Yamamoto, H. (1995). Synthesis of Alpha-Tocopherol: Scandium (III) Trifluoromethanesulfonate as an Efficient Catalyst in the Reaction of Hydroquinone with Allylic Alcohol. Bulletin of the Chemical Society of Japan, 68, 3569-3571.

Nong, K., Lu, D., Nong, R., Wei, Y., \& Huang,W. (2001). Research on the Synthesis of Lemonile by Dehydrat Ion through Phase T Ransfer Base Catalysis. Chemistry Society, 10, 3.

Packer, L., Rimbach, G., \& Virgili, F. (1999). Antioxidant Activity and Biologic Properties of a Procyanidin-Rich Extract from Pine (Pinus maritima) Bark, Pycnogenol. Free Radical Biology and Medicine, 27, 704-724. http://dx.doi.org/10.1016/S0891-5849(99)00090-8

Plotto, A., Barnes, K. W., \& Goodner, K. L. (2006). Specific Anosmia Observed for $\beta$-Ionone, but not for $\alpha$-Ionone: Significance for Flavor Research. Journal of Food Science, 71, 401-406. http://dx.doi.org/10.1111/j.1750-3841.2006.00047.x

Qian, D., Yao, L., Tan, Y., \& Cui, J. (1999). Catalyzed Synthesis of D-L- $\alpha$-tocopherol by Phosphomolybdic Acid. Synthesis Chemistry, 7, 2-4.

Zeng, L. H., Lian, H. M., Zhang, Q. (2012). Resources of Cinnamomum camphora and Its Utilization. Guangdong Forestry Science and Technology, 3, 014.

Qin, F., Shen, W., Wang, C., \& Xu, H. (2008). Selective Hydrogenation of Citral over a Novel Platinum/MWNTs Nanocomposites. Catalysis Communications, 9, 2095-2098.

Raju, V., Radhakrishnan, R., Jaenicke, S., \& Chuah, G. K. (2011). KF on $\gamma$-alumina: An Efficient Catalyst for the Aldol Condensation to Pseudoionones. Catalysis Today, 164, 139-142.

Robeson, C. D., Blum, W. P., Dieterle, J. M., Cawley, J. D., \& Baxter, J. G. (1955). Chemistry of Vitamin A. XXV. Geometrical Isomers of Vitamin A Aldehyde and an Isomer of Its $\alpha$-Ionone Analog. Journal of the American Chemical Society, 77, 4120-4125. http://dx.doi.org/10.1021/ja01620a044

Saddiq, A. A., \& Khayyat, S. A. (2010). Chemical and Antimicrobial Studies of Monoterpene: Citral. Pesticide Biochemistry and Physiology, 98, 89-93. http://dx.doi.org/10.1016/j.pestbp.2010.05.004

Sato, K., Kurihara, Y., \& Abe, S. (1963). Synthesis of Isophytol. The Journal of Organic Chemistry, 28, 45-47. http://dx.doi.org/10.1021/jo01036a009

Stubbs, B. J., Specht, A., \& Brushett, D. (2004). The Essential Oil of Cinnamomum camphora (L.) Nees and Eberm. Variation in Oil Composition throughout the Tree in Two Chemotypes from Eastern Australia. Journal of Essential Oil Research, 16, 200-205. http://dx.doi.org/10.1080/10412905.2004.9698697

Tang, J. (2011). Synthesis of Methyl Ionone. Hebei Chemical Industry, 34, 56-58.

Tanumihardjo, S. A. (2011). Vitamin A: Biomarkers of Nutrition for Development. The American Journal of Clinical Nutrition, 94, 658S-665S. http://dx.doi.org/10.3945/ajcn.110.005777

Wang, F., Wang, S., Hu, H., Huang, Q., Yang, D., Zhu, B., \& Liu, H. (2002). Raising Citral Content of Litsea cubeba Oil by Reduced-Pressure Distillation. Natural Products Research and Development, 14, 55-57.

Wang, L. (1990). Review of Preparation of $\beta$-Ionone. Chinese Journal of Pharmaceuticals, 21, 230-232.

Wang, Q., \& Jiang, J. (1993). Preparation of Citral and Synthesis of Ionones. Speciality Petrochemicals, 4, 20-22.

Ye, Q. (1992). Analysis of the Content of Aldehyde in the Esstenial Oil of the Litsea cubeba. Froestry Products and Processing Communication, 10, 18-20.

Yu, S. G., Anderson, P. J., \& Elson, C. E. (1995). Efficacy of $\beta$-Ionone in the Chemoprevention of Rat Mammary Carcinogenesis. Journal of Agricultural and Food Chemistry, 43, 2144-2147. http://dx.doi.org/10.1021/jf00056a035

Zhang, W., Lei, A., \& Zhao, Z. (2010). Synthesis of Pseudoionones over Solid Base Catalyst. Guangzhou Chemical Industry, 38, 157-162.

Zhou, X., Yu, Q., \& Guo, W. (2009). Synthetic Conditions of Pseudoionone. Journal of University of Science and Technology Liaoning, 32, 4-7. 
Scientific Research Publishing (SCIRP) is one of the largest Open Access journal publishers. It is currently publishing more than 200 open access, online, peer-reviewed journals covering a wide range of academic disciplines. SCIRP serves the worldwide academic communities and contributes to the progress and application of science with its publication.

Other selected journals from SCIRP are listed as below. Submit your manuscript to us via either submit@scirp.org or Online Submission Portal.
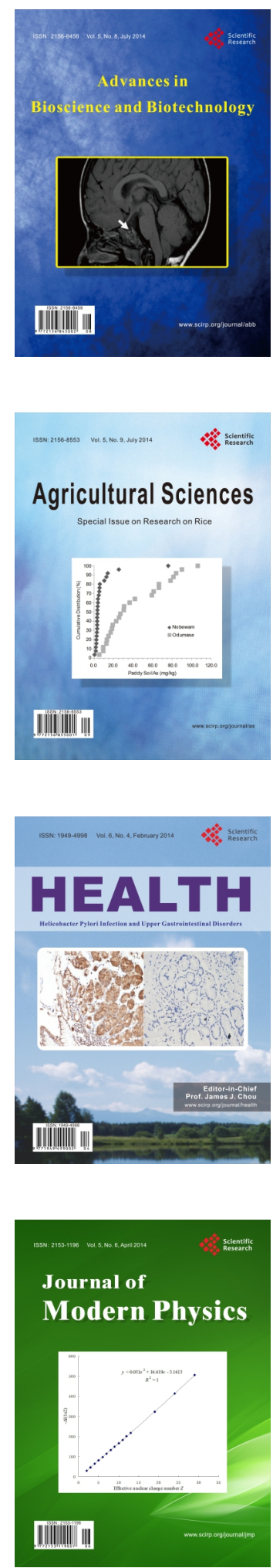
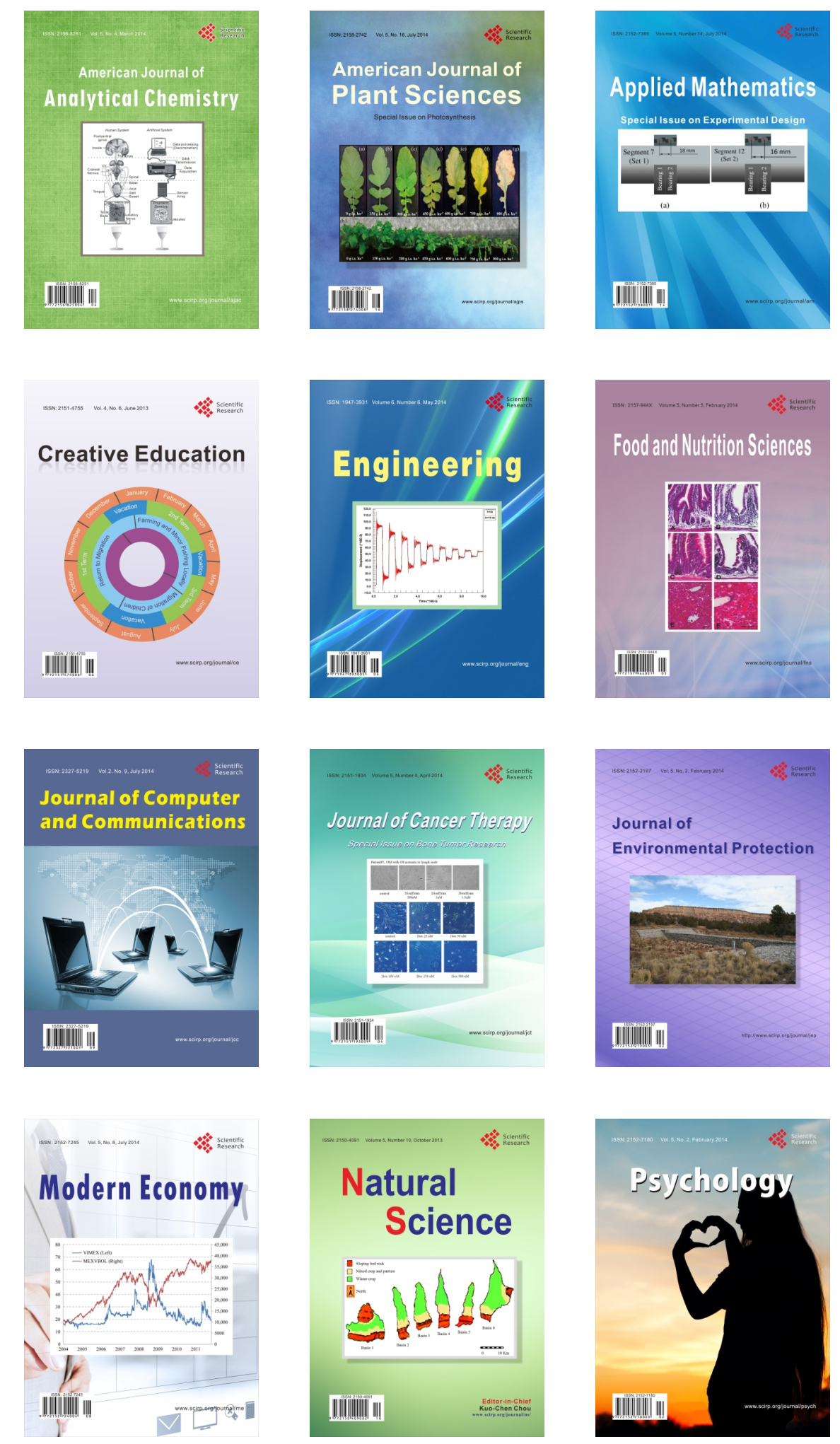